\title{
La lucha por la emancipación de Amauta y Repertorio Americano en el período de entreguerras
}

\author{
Daniel Iglesias Pinzas*
}

Recibido el 6 de marzo de 2020; aceptado el 10 de junio de 2020

\section{RESUMEN}

El presente artículo analiza la utilización política del pasado por parte de dos importantes revistas político-culturales entrelazadas por una serie de redes transnacionales. Explica el papel que desempeñaron tanto las redes como las revistas en la consolidación de una visión vanguardista de la cultura y de la historia de América Latina en el período de entreguerras. Examina igualmente el rol de las revistas en la circulación de una politización del tiempo por parte de las fuerzas antiimperialistas latinoamericanas basadas en Perú y Costa Rica.

Palabras clave: Revistas, redes transnacionales, antiimperialismo, cultura, historia.

\section{The fight for the emancipation of Amauta and} Repertorio Americano in the interwar period

\section{Abstract}

This paper analyzes the political use of the past by two important politicalcultural magazines intertwined by a series of transnational networks. 
Explains the role played by both networks and magazines in the consolidation of an avant-garde vision of culture and history of Latin America in the interwar period. It also examines the role of magazines in the circulation of time politicization by the Latin American anti-imperialist forces based in Peru and Costa Rica.

Key words: Reviews, transnational networks, anti-imperialism, culture, history.

$\mathrm{D}$

urante los años que siguieron al fin de la Primera Guerra Mundial, decenas de estudiantes e intelectuales no europeos -incluyendo aquellos provenientes de países colonizados - se incorporaron asiduamente en las filas de varios partidos políticos antiimperialistas, tal como lo hicieran el vietnamita Hô Chi Minh, quien en 1922 abrazó la Unión Intercolonia (una emanación del Partido Comunista Francés) o el argelino Messali Hadj, fundador en 1926 de la Estrella Norafricana. Gran parte de ellos estaban asentados en París ${ }^{1}$ y contribuyeron a la modernización del antiimperialismo mediante publicaciones culturales vanguardistas y una circulación epistolar de un nuevo tipo. Por primera vez, y de manera sistemática, construyeron redes profesionales globales para intercambiar, traducir y publicar textos novedosos que cambiaron el destino de las reivindicaciones políticas contra la dominación imperialista.

Paralelamente, otorgaron un espacio privilegiado a la producción artística con el fin de lograr una mayor emancipación cultural en las regiones no europeas, inclusive, si dicha politización de la cultura sirvió principalmente para consolidar un nacionalismo venido del Sur. Esta circulación de ideas de tendencia antiimperialista hizo posible la traducción y luego la aceptación local de diversos movimientos intelectuales europeos, tales como el sicoanálisis, el marxismo de tendencia leninista o el surrealismo, gracias al trabajo de referentes intelectuales como Romain Rolland (1866-1944), Waldo Frank (18891967), Henri Barbusse (1873-1935), Louis Aragon (1897-1982), entre otros, y de traductores a menudo anónimos. De esta manera, dichas generaciones redibujaron el rol del intelectual en el espacio público, confiriéndole un destino en la conducción de la transformación radical de las realidades nacionales.

La naturaleza transnacional del antiimperialismo de inicios del siglo XX goza de un gran consenso historiográfico. La mayoría de los trabajos ${ }^{2}$ habla

1 Goebel, Interwar Paris and the Seeds of the Third World Nationalism.

2 Gallichio, The African American Encounter with Japan and China: Black Internationalism in Asia, 1895-1945. Manela, The Wilsonian Moment: Self-Determination and the International Origins of Anticolonial Nationalism. Prashad, The Poorer Nations: A Possible 
de una convergencia global de las luchas políticas en los territorios no europeos y presenta la idea de que el tercermundismo comenzó en realidad durante las entreguerras. A pesar del interés por esta temática que nutre intensamente las publicaciones y manifestaciones científicas en el mundo entero, la historiografía nunca se interesó demasiado en las revistas que construyeron esta globalización intelectual ni en el rol que jugaron estas últimas. A menudo relegadas a la condición de simples soportes materiales al servicio de ideales políticos o artísticos, las revistas sólo aparecen indirectamente en las interpretaciones de la génesis de los movimientos emancipadores antiimperialistas, e inclusive, en las reconstrucciones de las trayectorias internacionales de los principales protagonistas de esos movimientos.

A pesar de estos pasos agigantados hacia una historia global ${ }^{3}$ del antiimperialismo latinoamericano, la historia intelectual mantiene todavía un cierto recelo hacia los enfoques que interpretan las revistas intelectuales de entreguerras como un nudo relacional entre varias redes de intelectuales orientados hacia una transformación radical de las mentalidades y de las representaciones sociales. No obstante, importantes trabajos ${ }^{4}$ han logrado poner en evidencia las prácticas de los grandes intelectuales latinoamericanos que se caracterizaban en su gran mayoría por una activa movilización de epistolarios, una sociabilidad compartida ${ }^{5}$ o un uso político de los objetos impresos. ${ }^{6}$ Es así como se han multiplicado las investigaciones sobre intelectuales latinoamericanos específicos que se interrogan de manera novedosa sobre la naturaleza relacional de los fenómenos de circulación intelectual, así como el papel que desempeñaban las publicaciones a la vez como relevo de las ideas que dormitaban en las correspondencias privadas y de laboratorios experimentales para aquéllos que creían que una transformación social radical o una revolución debían cultivar lazos fraternales con la liberación del arte y de la cultura.

Este renovado panorama historiográfico ha conseguido interpretar eficazmente las consecuencias de la internacionalización de las prácticas político-intelectuales de inicios del siglo $\mathrm{xx}$. Los estudios sobre redes

History of the Global South; Casaús Arzú, Pérez Ledesma (eds.), Redes intelectuales y formación de las naciones en España y América Latina (1890-1940); Louro, Comrades against Imperialism: Nehru, India and Interwar Internationalism.

3 Conrad, What is Global History?

4 Pita; Marichal, Pensar el antiimperialismo. Ensayos de historia intelectual latinoamericana (1900-1930); Devés Valdés, Redes intelectuales en América Latina. Hacia la constitución de una comunidad intelectual.

5 Bergel, “América, pero desde abajo. Prácticas y representaciones intelectuales de un ciclo histórico latinoamericanista (1898-1936)”.

6 Bergel, "Para una historia de la no-lectura en América Latina. Los usos de los objetos impresos en el proceso de popularización del Partido Aprista Peruano (1931-1945)”. 
intelectuales ${ }^{7}$ en particular han mostrado la diacronía de los lazos de confianza recíproca que influyeron en la trayectoria de cada uno de los personajes estudiados. Aunque estos trabajos son de gran utilidad para analizar la importancia del ámbito relacional propio al intelectual latinoamericano de dicha época, no logran todavía desprenderse de una visión horizontal de los lazos y suma de relaciones de los intelectuales. Como lo pone en relieve Mustapha Emirbayer en su célebre manifiesto de sociología relacional, ${ }^{8}$ la comprensión del impacto, tanto de las redes sociales como de los entornos relacionales, debe también tomar en consideración la verticalidad de los lazos interpersonales dentro de una red social, es decir, las luchas de poder (en un sentido más amplio) o las trabas que existen cuando un individuo desea desplegar su agencia individual. Según este sociólogo, cercano a la tradición inaugurada por Pierre Bourdieu, los estudios que no exploran la verticalidad de las configuraciones interpersonales no ven, desde luego, los elementos cotidianos claves que constituyen y definen a la vez el comportamiento de una persona, tanto fuera como dentro de una red. Pasan por consiguiente de largo delante de la verdadera dimensión social que supone formar parte de una red social y que explica cómo se forman o deshacen en el tiempo las distintas estructuras interpersonales ${ }^{9}$ que le dan vida a cualquier tipo de espacio social.

Las investigaciones que examinan simultáneamente la verticalidad y la horizontalidad de los lazos interpersonales dentro de una red social son poco numerosas. Existe incluso una pugna dentro del campo del análisis de redes sociales que enfrenta partidarios del estudio de la verticalidad a defensores de la única observación de la horizontalidad. Estos dos enfoques han fomentado desde luego, dos metodologías antagónicas y provocado la invisibilidad de cualquier tipo de propuesta alternativa. La culpa de una voluntad ciega de restarle importancia a los elementos exteriores que frenan, o al contrario, consolidan la agencia individual dentro de una red social. Prueba de ello son, por ejemplo, los trabajos que abordan el papel de fronteras simbólicas ${ }^{10}$ para el advenimiento de redes intelectuales. Estos novedosos enfoques suelen en efecto, pasar desapercibidos frente a los análisis históricos cuantitativos a pesar de ser capaces de poner al descubierto la naturaleza social de la agencia individual. Cercanos a la tradición de la microhistoria italiana, con quien

7 Pita, Redes intelectuales en América Latina; Yankelevich, "Las redes de solidaridad latinoamericana: José Ingenieros y Alfredo Palacios frente a la Revolución Mexicana”.

Emirbayer, "Manifiesto for a relational sociology".

Boissevain, Friends of friends: networks, manipulators and coalitions.

10 Pita, "Fronteras simbólicas y redes intelectuales. Una propuesta"; Ansell, "Symbolic Networks: The Realigment of the French Working Class, 1887-1894”. 
comparten una visión cultural de la agencia individual, logran, sin embargo, mostrar muy bien los límites dentro de las redes sociales, así como los frenos culturales que existen dentro de las acciones colectivas.

A nivel de la historia intelectual del antiimperialismo, vabe la pena mencionar el poco interés de los historiadores frente a la problemática del carácter cultural de la agencia individual de los principales protagonistas de este movimiento político. Esto merece la pena de ser subrayado, puesto que el antiimperialismo de entreguerras se basaba en una idea de "emancipación” que no solamente aparecía como una voluntad de ruptura con un orden político heredado, sino también como el punto de partida de un movimiento de liberación de los pueblos, entendido como una ruptura temporal sin retorno. Se trataba de un llamado a un cambio profundo de mentalidad, de racionalidad, así como a una nueva adecuación con la realidad histórica del momento. A pesar de las evidentes diferencias de recepción en el seno de revistas culturales cercanas a esta tendencia ideológica, esta propuesta de cambio hegemónico puede ser leída como un programa de formación ideológico que influyó sobre la agencia individual de los militantes y simpatizantes de esta corriente política. Puede igualmente ser vista como una doctrina que intentó forjar un nuevo "ser antiimperialista”, sobre todo en América latina ${ }^{11}$ donde los periódicos como Amauta y Repertorio Americano, y los movimientos internacionalistas, como la Alianza Popular Revolucionaria Americana (APRA, 1926-1930), actuaron como agentes de una nueva vanguardia político-intelectual. Es por eso que esta búsqueda de emancipación antiimperialista latinoamericana puede leerse a la vez como parte integrante de una historia de la globalización política y como una de las expresiones de la internacionalización de las radicalidades político-culturales regionales sectorizadas.

América Latina atravesó el movimiento de emancipación antiimperialista del período de entreguerras en una situación política muy diferente a la que se vivía en Asia y en África. Las luchas locales siguieron una temporalidad regional singular sobre las huellas de las desilusiones ante el centenario de las independencias de inicios del siglo XIX, y frente a un modelo europeo en crisis por los estragos de la Primera Guerra mundial. ${ }^{12}$ Además, la mayoría de los países latinoamericanos se encontraban en una etapa de cuestionamiento de su identidad a partir de 1910, luego de la publicación de una serie de escritos sobre la necesidad de salir de un modelo de sociedad oligárquica. En este contexto de búsqueda de identidad sobre un fondo de redefinición

11 Siskind, Cosmopolitan Desires: Global Modernity and World Literature in Latin America.

12 Compagnon, L'Adieu à l'Europe. L'Amérique latine et la Grande Guerre (Argentine et Brésil, 1914-1939). 
nacionalista los intelectuales latinoamericanos, como el mexicano José Vasconcelos (1882-1959) o el argentino Manuel Ugarte (1875-1951), tejieron lazos estrechos entre las mujeres y los hombres comprometidos con los combates anticoloniales. Para algunos, esta alianza participaba de una sociabilidad política en ciudades como París, ${ }^{13}$ donde se reunían en ocasión de las numerosas fiestas de solidaridad, conferencias universitarias, reuniones de apoyo y manifestaciones artísticas e inclusive, en las aulas de la universidad, como era el caso de la Sorbona. Algunos de los grandes pensadores, a semejanza del intelectual mexicano Alfonso Reyes (1889-1959) o de artistas de renombre, como el muralista mexicano Diego Rivera (1886-1957), mantuvieron correspondencia privada con referentes del medio artístico europeo e inclusive con poetas no europeos, a imagen de la relación que unía a la intelectual argentina Victoria Ocampo (1890-1979) con el poeta hindú Rabindranath Tagore ${ }^{14}$ (1861-1941).

Las revistas que nos interesan aquí, Amauta (1926-1930) y Repertorio Americano (1919-1959), crearon nuevos espacios político-intelectuales donde circulaban manifiestos políticos, poemas, caricaturas, grabados, textos de historia, análisis geopolíticos y textos filosóficos. Dirigidas por comités de redacción restringidos, propiciaron la aparición de una mediación internacional entre intelectuales de un nuevo estilo gracias al trabajo de cooperación entre traductores y colaboradores venidos de los cuatro rincones del mundo. Afirmaron su determinación de llevar sus luchas y expresiones artísticas a un nivel internacional, así como su creencia compartida de que las publicaciones ocupaban la punta de lanza de las luchas vanguardistas. Fundada en San José, Repertorio Americano permitió en particular la circulación de movimientos culturales en América Latina, ya que le dedicó la gran mayoría de sus ejemplares a la renovación del pensamiento latinoamericano. De la mano de su fundador, Joaquín García Monge, actuó como un verdadero puente intelectual a nivel continental y al mismo tiempo acompañó la militancia política de su creador, quien participó junto con Carmen Lyra (educadora y gran artífice de esta revista) en la fundación del Partido Alianza de Obreros, Campesinos e Intelectuales (1929), organización considerada como la primera ideología de Costa Rica y que se disolvió en 1931 para darle paso al Partido Comunista de Costa Rica. Amauta no se quedó atrás. Fundada en Lima por José Carlos Mariátegui, la revista desempeñó un papel clave en la reivindicación de los orígenes indios del continente americano y en la transformación progresiva de demandas étnicas y

13 Taracena, “La Asociación General de Estudiantes Latinoamericanos de Paris (1925-1933)”, pp. 61-80.

14 Ocampo, Tagore en las barrancas de San Isidro. 
sociales en programas políticos de corte marxista adaptados a la realidad latinoamericana. Asociada al antiimperialismo latinoamericano y al renacimiento del pensamiento autóctono andino, siguió progresivamente el pensamiento revolucionario de su fundador, quien rompió ideológicamente con Víctor Raúl Haya de la Torre para fundar el Partido Socialista Peruano, que pasaría a llamarse Partido Comunista del Perú en 1930.

El presente artículo retoma este fenómeno de emancipación política y cultural en la América Latina hispanohablante. A partir del estudio de revistas poco valoradas como redes transnacionales quisiéramos explicar, en un primer momento, la génesis de un tipo de ideologización de la cultura. Luego, en un segundo momento, insistiremos sobre el "régimen de historicidad” 15 propio de esas manifestaciones político-intelectuales. Desde un punto de vista metodológico, esto supone explicar primero los modos de circulación de las ideas que dieron nacimiento a las revistas estudiadas. Luego, esto conduce a utilizar heurísticamente el concepto de "régimen de historicidad", el cual permite explicitar la relación que mantiene una sociedad con el pasado, el presente y el futuro, particularmente en tiempos de crisis, como sucedió durante las conmociones del período de entreguerras en América Latina. Se trata específicamente de ver cómo las redes intelectuales pueden funcionar como redes simbólicas donde la articulación en los discursos sobre el pasado logra una acuidad muy significativa. Se trata finalmente de explicar por qué las redes transnacionales son capaces de transformar el pasado en sujeto político como "una utilización del pasado para moldear mejor el presente”. 16

\section{LOS FUNDAMENTOS INTELECTUALES DE UN NUEVO ANTIIMPERIALISMO}

Las propuestas de los pensadores latinoamericanos, como los argentinos José Ingenieros (1877-1925) y Manuel Ugarte (1875-1951) o los peruanos José Carlos Mariátegui (1894-1930) y Magda Portal (1900-1989), entre otros, frente a las problemáticas antiimperialistas, se asocian tradicionalmente a sus trayectorias individuales. Según el filósofo José Alberto de la Fuente, fundador del APRA, el peruano Víctor Raúl Haya de la Torre (18951979), por ejemplo, comenzó a interesarse en el tema de la dominación imperialista con el objetivo de "proteger los intereses, recursos y sociedades

15 Hartog, Régime d'historicité. Présentisme et expérience du temps.

16 Giddens, The consequences of modernity, p. 54. 
latinoamericanas del imperialismo estadounidense”. ${ }^{17}$ Otros trabajos ${ }^{18}$ comparativos sobre la trayectoria de referentes antiimperialistas regionales señalan contrariamente que el tema de la internacionalización de los combates político-intelectuales estaba lejos de ser una evidencia durante los años 1920-1930. Estos trabajos se basan en posiciones como las de Alfonso Reyes, quien pensaba que no existía ningún lenguaje ideológico común capaz de federar a las diferentes facciones antiimperialistas latinoamericanas.

Sin minimizar el carácter excepcional de ciertas sendas individuales o de redes intelectuales, las raíces de este antiimperialismo siguen estando ligadas, sobre todo, al desarrollo de una crítica ideológica de la colonización española y de sus consecuencias nefastas sobre la historia de los pueblos precolombinos. Esta crítica está presente en acontecimientos históricos como la Revolución mexicana de 1910 o la Reforma Universitaria de Córdoba de 1918, pero sobre todo, en movimientos intelectuales mayores (el Indigenismo, por ejemplo) de inicios del siglo xx latinoamericano. Esta condena a la colonización española estaba igualmente muy presente en América Latina cuando los intelectuales explicaban los males del presente como el fruto de una herencia destructora. Según esta lectura del pasado, la Conquista había producido una ruptura temporal irreversible a causa de la destrucción de los fundamentos culturales locales mediante la instalación de un sistema de explotación.

Los textos vanguardistas fueron poderosos relevos de una interpretación histórica que señalaba principalmente tres consecuencias mayores ligadas a la colonización: la muerte de millones de personas en las Américas, la explotación ininterrumpida de las poblaciones autóctonas y la destrucción del conjunto de los vínculos sociales dentro del mundo indígena. La revista peruana vanguardista Amauta hizo de esta denuncia uno de los fundamentos de su combate por la definición de la modernidad latinoamericana y tuvo, gracias a ello, una resonancia considerable en las redes antiimperialistas de entreguerras. Según la revista vanguardista argentina Martín Fierro, se trataba inclusive de crear una nueva "sensibilidad" de manera a construir una respuesta cultural global contra los múltiples adversarios de las transformaciones culturales.

Como todo movimiento de fuerte connotación ideológica, el antiimperialismo latinoamericano vehicula símbolos que encarnaban las desigualdades socioeconómicas en América Latina. La expresión más lograda de esta denuncia fue llevada por la figura del "Indio” o más bien, por la representación

17 De la Fuente, “Víctor Raúl Haya de la Torre, el APRA y el indoamericanismo”, p. 88.

18 Hodge Dupré, "La defensa continental de América Latina en el pensamiento de Manuel Ugarte Víctor R. Haya de la Torre (1900-1945)”, p. 160; Funes, Salvar la nación: intelectuales, cultura y política en los años veinte latinoamericanos. 
de este último en la fotografía, los grabados o inclusive en los dibujos publicados por la prensa. Según esta representación, el "Indio” deviene símbolo de la pobreza y de la explotación causadas por un sistema socioeconómico que posee una temporalidad propia y genera ciclos perpetuos de desigualdades en el seno de las sociedades latinoamericanas. A diferencia de la tradición oligárquica prevaleciente en estas sociedades, los artículos defendían el principio según el cual el "Indio” poseía una agentividad que los intelectuales debían hacer resurgir en múltiples niveles políticos, sociales, humanos, identitarios, etcétera. En la revista Amauta, por ejemplo, se planteaba que esta capacidad de actuar de las culturas americanas autóctonas debía conjugarse con los esfuerzos a realizar en materia de integración nacional mediante la puesta en marcha de políticas educativas destinadas a los más pobres. Según esta lógica, las masas autóctonas llamadas “indias” debían ser integradas a una nueva comunidad nacional nacida del diálogo entre las tradiciones precolombinas y una influencia cultural española juzgada inevitable: “el hombre y las sociedades americanas del futuro no podrán dejar de tener raíces profundamente hispánicas a pesar de que lo nieguen. Su cultura será una cultura española evolucionada”. ${ }^{19}$

Los temas políticos fueron una preocupación permanente en las revistas vanguardistas, así como los manifiestos políticos y los artículos sobre la coyuntura internacional. De este modo, las publicaciones se convirtieron en espacios de construcciones culturales utópicas, al mismo tiempo que respuestas intelectuales a un contexto de crisis internacional. A partir de 1925, las revistas tomaron otro giro cuando la represión autoritaria se acentuó en América Latina y generó una ola de exilios políticos sin precedentes. Las violaciones sistemáticas de las libertades públicas pasaron entonces a ocupar un lugar importante en las publicaciones que no dudaron en recolectar tanto denuncias como testimonios ${ }^{20}$ contra los gobiernos autoritarios. Este fenómeno se acentuó a medida que varios países se hundían en la violencia política, como venía sucediendo en la Nicaragua del guerrillero Augusto Sandino (1895-1934) o en la Cuba que resistía contra la dictadura de Gerardo Machado (1925-1933). El mundo intelectual jugó aquí un papel clave para transformar en dichas resistencias anti-autoritarias en símbolos de las luchas emancipadoras contra la política extranjera de los Estados Unidos.

19 Blanco Fombona, "El concepto de Independencia surge en Hispanoamérica para obtener la independencia económica”, Repertorio Americano, San José de Costa Rica, núm. 3, 1925, p. 33.

20 “Manifiesto”, Repertorio Americano, núm. 14, 1929, pp. 231; Apra, “Estados Unidos juega a la paz en Europa y hace la guerra en la América latina”, Repertorio Americano, núm. 7, 1930, pp. 106-107; Del Valle, "La hora de nuestra América”, Amauta, núm. 7, 1927, pp. 1820; Ugarte, "Manifiesto a la juventud latinoamericana”, Amauta, núm. 8, 1927, pp. 37-39. 
La revista cubana Atuei, publicada esporádicamente entre noviembre de 1927 y agosto de 1928, fue en ese contexto, la portavoz de la vanguardia estética por su compromiso contra el "imperialismo yankee" en los países latinoamericanos. Órgano de la sección cubana del APRA, denunció en su segundo número, por ejemplo, la doctrina Monroe de 1823, que había transformado a la América Latina en una zona de influencia norteamericana y llamó abiertamente a recuperar "nuestras tierras, nuestro azúcar, nuestro petróleo, nuestras minas, nuestros bosques, nuestra libertad". ${ }^{21}$ Por otro lado, esta publicación contribuyó al desarrollo de una lectura ideológica y antiimperialista del pasado latinoamericano, en particular en su tercer número, el cual conoció una gran circulación en las redes intelectuales gracias a la movilización de figuras de las independencias latinoamericanas, como Francisco de Miranda y sobre todo, de Simón Bolívar. Numerosos artículos teóricos o artísticos fortalecieron luego esta visión crítica de la historia de las independencias y contribuyeron progresivamente a convertirla en una de las líneas matrices del antiimperialismo latinoamericano.

\section{MEDIADORES Y MEDIACIONES TRANSNACIONALES DE UNA EMANCIPACIÓN ANTIIMPERIALISTA}

El pensamiento emancipador latinoamericano se desarrolló en espacios intelectuales heterogéneos y complejos, a causa de la naturaleza misma del tejido social sobre el cual reposaba. Cada artículo, manifiesto o traducción suscitó negociaciones antes de su publicación y no escapó a la necesidad de una adaptación cultural regional, con el fin de que los intercambios Sur/Sur ${ }^{22}$ pudieran contrarrestar la distancia existente entre las realidades nacionales tomadas en cuenta. Si bien fue internacionalista, la emancipación antiimperialista en tanto fenómeno político-intelectual, no puede únicamente interpretarse por medio de simples modelos circulatorios. Cada vanguardia siguió, en realidad, su propia temporalidad y sus propios objetivos, a partir de contextos políticos, más o menos difíciles. La existencia de particularidades locales no fue un obstáculo al mantenimiento de contactos sostenidos con las redes transnacionales que hacían circular la información a escala internacional.

Esta conexión de manifestaciones antiimperialistas en varias ciudades del mundo estaba entonces asegurada, sea a través de una intensa sociabilidad, ${ }^{23}$ sea por medio de espacios de mediación o a través de las revistas intelectua-

21 “Manifiesto”, Atuei, núm. 3, 1927, p. 1.

22 Klengel, Ortiz Wallner, Sur/South Poetics of Thinking Latin America/India.

23 Goebel, "Fighting and Working in the Metropole: The Nationalizing Effects of the First War Throughout the French Empire, 1916-1930”, pp. 101-111. 
les que circulaban a nivel mundial. Los periódicos y revistas sirvieron desde entonces como puntos de reencuentro entre contemporáneos, de relanzamiento de ciertos textos publicados anteriormente y de visibilidad para los autores provenientes de países lejanos o fallecidos, pero sobre todo, de nudo relacional entre varias redes heterogéneas que incluían autores, traductores, comunicadores, hombres políticos e incluso diplomáticos. Estas publicaciones crearon, en consecuencia, una red concreta de simpatizantes e hicieron visibles los debates subterráneos, a menudo limitados a pequeñas esferas intelectuales locales.

En América del Sur, los redactores de Martin Fierro, por ejemplo, se fijaron como misión renovar completamente el arte argentino, incluyendo en sus páginas a la juventud estudiantil contestataria ${ }^{24}$ y las nuevas figuras ${ }^{25}$ de la escena literaria de Buenos Aires, como los argentinos Jorge Luis Borges (1899-1986) y Raúl González Tuñón (1905-1974). A pesar de tener una orientación inicial que buscaba la transformación del arte, ${ }^{26}$ el contexto político del período de entre-guerras terminó por impregnar profundamente la mayoría de las producciones artísticas, así como las discusiones sobre las identidades nacionales. Su resultado fue, entonces, una politización de los contenidos editoriales y un aumento de las publicaciones de artículos antiimperialistas con el fin de sensibilizar a los lectores sobre la urgencia revolucionaria.

Esta ola emancipadora se consagró a eliminar las tradiciones nacionales y oligárquicas vigentes. Con este propósito se movilizó a la "vanguardia” en su acepción militar original, es decir, la organización de un grupo humano en torno a valores comunes, a una ética compartida y discursos unificadores a imagen de los manifiestos. Frente a las crisis, a las dificultades o a los actos de represión política, las revistas encontraron en las redes transnacionales de solidaridad un punto de apoyo a la vez formal e informal, que les permitió constituirse y, luego sobrevivir. En 1925, el peruano José Carlos Mariátegui, director de Amauta, escribió así a Joaquín García Monge (18811958), director de Repertorio Americano:

Preparo una revista mensual, para la cual reclamo su colaboración. Creo que podríamos efectuar un pequeño intercambio entre esta revista y Repertorio Americano, canjeando una cantidad de números en proporción equivalente. Repertorio Americano se vendería así en la librería Minerva. Estoy seguro de

24 “Los maestros rebeldes”, Martín Fierro, núms. 5-6, 1924, p. 37; Gómez, "Balada a un estudiante lugonófogo, melenudo y platense”, Martín Fierro, núms. 14-15, 1925, p. 1.

25 Gónzalez Lanusa, “Las revoluciones literarias”, Martín Fierro, núm. 3, 1927, p. 2; Méndez, “Rol de Martín Fierro en la renovación poética actual”, Martín Fierro, núm. 38, 1927, p. 2.

26 José Carlos Mariátegui, “Arte, Revolución y Decadencia”, Amauta, núm. 3, 1926, pp. 3-4. 
que puede tener asiduos lectores. Oliverio Girondo cuando estuvo en Lima, me anunció su propósito de organizar, en esta forma, un extenso y constante intercambio entre las revistas y grupos intelectuales de nuestra América. ${ }^{27}$

A nivel de la organización, intelectuales de renombre mundial, como Waldo Franck y José Vasconcelos, se encargaron de escribir cartas destinadas a la opinión pública y a contactar directamente a los colaboradores de los artículos. En este marco, la figura de Haya de la Torre se volvió fundamental en la elaboración de una red de colaboradores, puesto que no cesó de enviar misivas pidiendo que se unieran al combate de la vanguardia intelectual antiimperialista. Este último entró en contacto con eminentes figuras internacionales, como el célebre escritor francés pacifista Romain Rolland, a quien le pidió manifiestos con el fin de publicarlos en Amauta y Repertorio Americano. Podemos apreciar a continuación la importancia de su red egocéntrica durante el período de entreguerras, ya que destacan en ella una serie de lazos interpersonales entre figuras literarias, intelectuales, políticos o artistas de todas las nacionalidades (Gráfico 1).

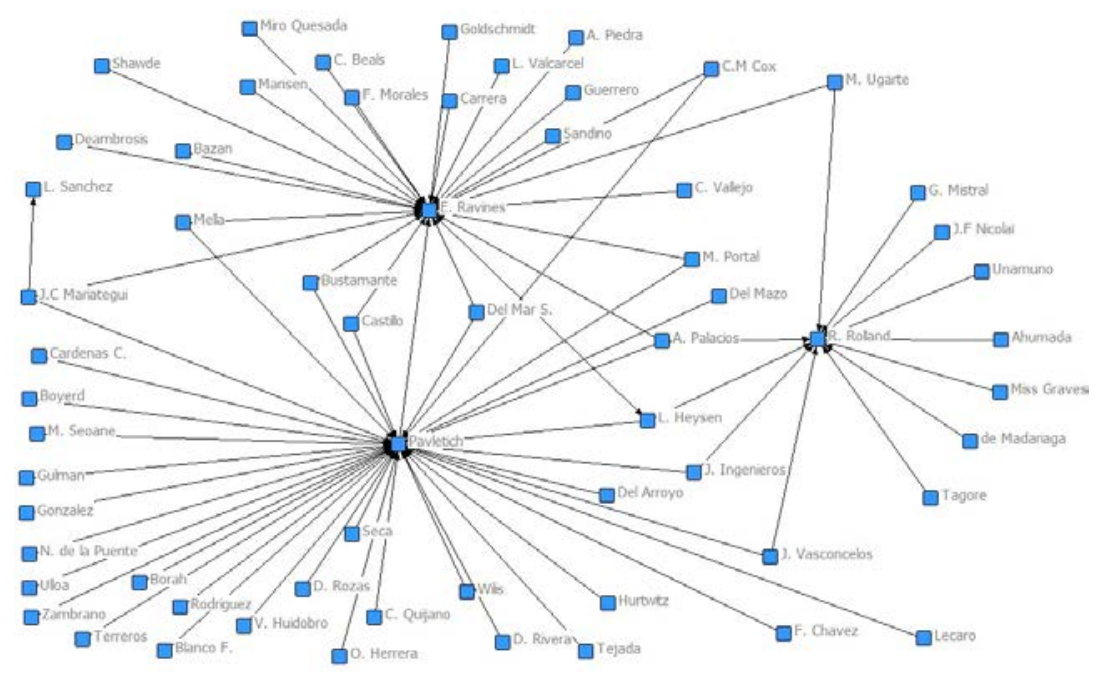

Gráfico 1. Red egocéntrica de Haya de la Torre (1924-1930).

Fuente: correspondencia de Haya de la Torre con Esteban Pavletich, Eudocio Ravines y Romain Rolland.

27 Carta de José Carlos Mariátegui à Joaquín García Monge, Lima, 24 de diciembre de 1925, Archivo digital José Carlos Mariátegui: http://archivo.mariategui.org/index.php/ 
Este desafío era aún más importante para el éxito de esas publicaciones, puesto que muchos de los miembros de esa vanguardia compartían una cultura política y referencias intelectuales, lo que facilitaba en gran medida la problemática de la aceptación de un programa de emancipación políticointelectual extremadamente complejo. Las revistas contribuyeron así a la instauración de un discurso político programático que fue eficaz cuando, a partir de 1927, los estudiantes latinoamericanos en Europa, así como los exiliados políticos, apoyaron las reivindicaciones políticas antiimperialistas. Las manifestaciones de esta adhesión fueron ciertamente algo disparatadas, pero crearon una verdadera dinámica colectiva en las principales ciudades donde circulaban las publicaciones. La ciudad de París, por ejemplo, se transformó a partir de 1926 en un centro neurálgico de este nuevo pensamiento latinoamericano. Así, podemos leer en el número 4 de Amauta, una carta de Haya de la Torre dirigida a Mariátegui:

Querido compañero Mariátegui: Al volver esta noche de París donde queda fundado y en pleno trabajo el grupo de jóvenes peruanos que van a dirigir las actividades de la A.P.R.A en Europa, me he encontrado con el primer número de AMAUTA, que es el mejor mensaje que yo podía haber deseado por parte de la sección de los trabajadores intelectuales del Perú, militantes en nuestro gran frente de acción, que, con los trabajadores manuales, va a conquistar para el país los caminos de la justicia. ${ }^{28}$

Dentro de este esquema, otras grandes figuras utilizaron sus relaciones en las redes de escritores europeos con el objeto de convencer a los autores no latinoamericanos a que aceptaran la traducción y posterior publicación de sus escritos. Fue el caso de la poeta chilena Gabriela Mistral (1889-1957), quien utilizó su estatus de diplomática ante las autoridades de la organización internacional de cooperación intelectual para tejer lazos y facilitar la circulación de producciones intelectuales latinoamericanas en Europa ${ }^{29}$ y viceversa. En su correspondencia con el director de Repertorio Americano, Joaquín García Monge, insistió sobre la necesidad de abrir las páginas de las publicaciones a los amigos escritores exiliados, a intelectuales como el francés Louis Aragon, así como a los temas relativos a las nuevas pedagogías vigentes en Europa en el período de entreguerras.

Gabriela Mistral jugó un rol clave en la introducción de los nuevos métodos pedagógicos en América Latina, especialmente gracias a sus escritos

Haya de la Torre, "Nuestro frente intelectual”, Amauta, núm. 4, 1926, p. 3.

29 Dumont, Diplomatie culturelle et fabrique des identités. Argentine, Brésil, Chili (19191946). 
sobre la enseñanza en las escuelas primarias y la lectura en los niños, publicados en Repertorio Americano. ${ }^{30}$ Otras personalidades, como el historiador y literato peruano Luis Alberto Sánchez (1900-1994), fundaron empresas editoriales durante sus años de exilio y frecuentaron los departamentos de letras de las universidades latinoamericanas para continuar divulgando las reivindicaciones de la lucha antiimperialista entre los profesores universitarios norteamericanos de renombre. Estos roles de mediadores internacionales estuvieron ligados a la naturaleza misma de la construcción de una vanguardia político-intelectual, ya que ésta consideraba que toda actitud iconoclasta debía ser una manifestación permanente - a niveles nacional e internacional - en nombre de una modernidad por venir que rompiera con el orden establecido.

Más allá de los méritos individuales, este tipo de trayectorias confirma la importancia que tenían los grandes intelectuales dentro de las redes antiimperialistas latinoamericanas. El caso del entorno relacional cercano de Haya de la Torre (Gráfico 2) dentro de la red egocéntrica del líder político venezolano Rómulo Betancourt en 1931 demuestra incluso el grado de cercanía relacional que existía entre dichas figuras. A continuación podemos ver que los epistolarios entre Haya de la Torre y Betancourt hacían referencia a intelectuales como García Monge, Romain Rolland y Magda Portal. Estas menciones desempeñaban un papel político puesto que subrayaban la necesidad de estrechar lazos, de desarrollar estrategias comunes y de crear puentes para hacer prosperar los proyectos antiimperialistas. La presencia abundante de estos vínculos dentro de la correspondencia entre dos líderes históricos de la política sudamericana permite, desde luego, dibujar facciones políticointelectuales dentro de la red egocéntrica de Betancourt y ver los matices de dicha red según la naturaleza o perfil de sus miembros. En ese caso, Haya de la Torre era un intermediario internacional, ya que le permitía a Betancourt acceder a importantes espacios antiimperialistas.

Si miramos incluso más de cerca el perfil de la red cruzada de los activistas Betancourt y Haya de la Torre en sus años de juventud (Gráficos 1 y 2), observamos que las cartas mencionaban a intelectuales de distintas nacionalidades pertenecientes a distintas facciones o grupos políticos. Los espacios relacionales de estos dos hombres confirman que las fronteras que supuestamente dividían el campo intelectual latinoamericano no existían en realidad. Por otro lado, este enfoque cuantitativo de dos epistolarios cruzados pone de relieve un dato fundamental: el uso político de revistas culturales era el resultado de acciones colectivas a la vez complejas y muy elaboradas.

30 Mistral, “A los maestros de Costa Rica”, Repertorio Americano, núm. 9, 1924, p. 6; Mistral, “El método Decroly”, Repertorio Americano, núm. 15, 1927, p. 15. 
La naturaleza política de la emancipación buscada por Repertorio Americano y Amauta puede, por lo tanto, también ser vista como el producto de la suma de varios universos relacionados.

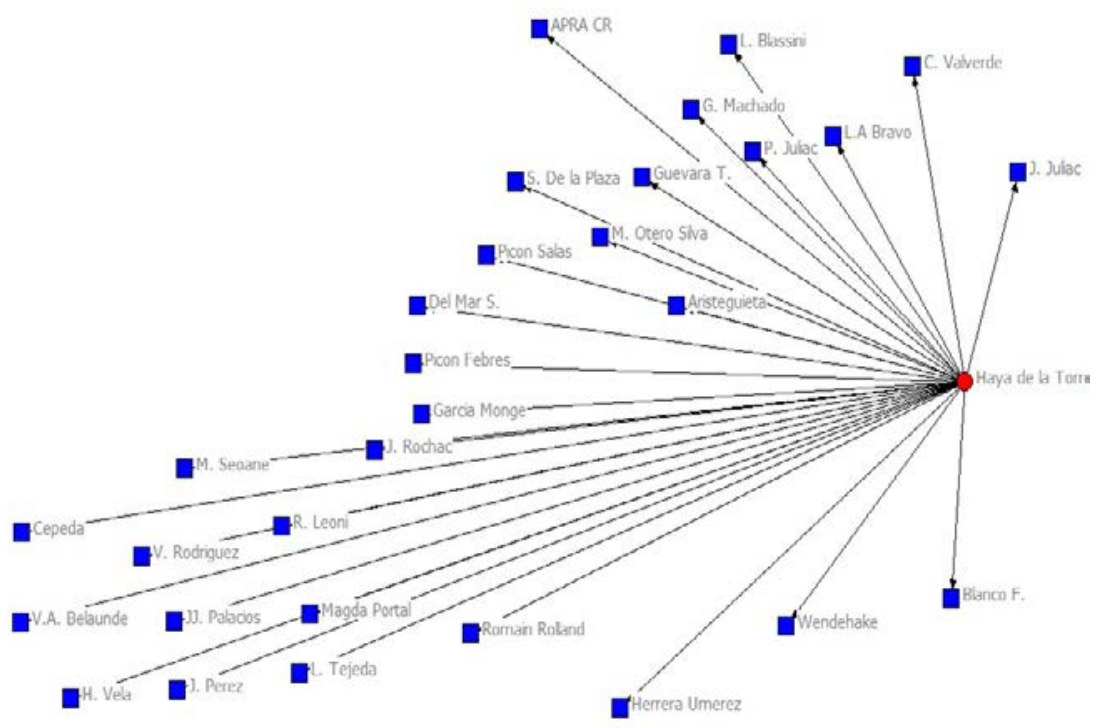

Gráfico 2. Facción de Víctor Raúl Haya de la Torre dentro de la red egocéntrica de Rómulo Betancourt (1931).

Fuente: correspondencia privada de Rómulo Betancourt.

\section{LA EMANCIPACIÓN DEL PASADO Y LA CONSTRUCCIÓN DEL PRESENTE ANTIIMPERIALISTA}

Como toda empresa historiográfica, la selección de artículos históricos por los comités de redacción se funda sobre una pluralidad de puntos de vista en torno a las cronologías nacionales. La apertura a la historia, tanto local como internacional, en el seno de las revistas antiimperialistas latinoamericanas, se hizo en función de las afinidades personales de los redactores, así como de su interés por esas temáticas. La interpretación del pasado latinoamericano se transformó, sin embargo, en una cuestión central del combate por la emancipación, a medida que este pasado se convertía en un desafío político tanto en la región como a nivel internacional durante el período de entregue- 
rras. En efecto, el contexto ideológico de la época estaba muy marcado por las múltiples historicidades políticas que buscaban movilizar el pasado con fines de propaganda política. Al igual que "el tiempo mesiánico revolucionario" comunista o el "tiempo de la naturaleza" del nazismo, nadie podía en ese entonces ignorar en los medios politizados, la importancia del pasado en la construcción de la unidad nacional y de las clases sociales, así como el poderío simbólico de los héroes, de los lugares de memoria y de las fechas históricas.

Cuando retrocedemos en el tiempo y analizamos más en detalle el período de entreguerras como marco temporal ${ }^{31}$ nos topamos incluso con pugnas memoriales que resaltaban la absoluta novedad de dicha época. A pesar de las diferencias entre los distintos bandos políticos, las nuevas generaciones compartían entonces la creencia de que cada una de ellas era la depositaria de una misión regeneradora que debía engendrar una nueva temporalidad. Los discursos históricos debían por lo tanto ser experimentados por sus autores y lectores como una "experiencia del tiempo histórico" que debía promover valores morales y políticos. La historia era una herramienta política que debía ser reapropiada para inscribir un accionar político en el tiempo, imponer una manera de pensar los orígenes culturales, pero sobre todo, para diseñar narrativas sobre los eventos pasados necesarios a las luchas del presente.

Esta ideologización del pasado se tradujo en el desarrollo de una visión dialéctica de este último construida de preferencia como una oposición permanente entre los países colonizadores y los países colonizados, con énfasis en las desigualdades económicas y de acceso a los saberes tecnológicos. Bajo formas muy diversas (artículos, imágenes de propaganda, manifiestos, actos de conmemoración), esta reapropiación política de la historia le dio tribuna a una joven generación que participó en la elaboración de su propia identidad histórica. ${ }^{32}$ Fueron las acusaciones contra los perjuicios de la modernidad occidental en América Latina las que le dieron a esas interpretaciones un tono antiimperialista. ${ }^{33}$ Por ende, denunciaban el sistema de explotación a escala global, nacido con la modernidad europea del siglo XV, como el principal responsable de las desigualdades socio económicas entre el mundo occidental y los países latinoamericanos.

31 Löwy, “Temps messianique et historicité révolutionnaire chez Walter Benjamin”; Chapoutot, "L’historicité nazie”.

32 Haya de la Torre, "El problema histórico de nuestra América”, Amauta, núm. 12, 1928, pp. 12-15; Bejarano, “Tengamos fé en nuestra raza”, Amauta, núm. 13, 1928, pp. 32-33.

33 Restrepo, “Dollar Diplomacy - Diplomacia del Dólar”, Repertorio Americano, núm. 9, 1927, pp. 1-2; Wyld Ospina, "La nacionalización de las tierras como medio defensivo”, Repertorio Americano, núm. 2, 1929, pp. 1-2. 
Los artículos de carácter histórico insistían particularmente sobre la tesis, según la cual, la dominación imperialista reposaba sobre una circulación desigual de los saberes a nivel mundial. ${ }^{34}$ Se trataba de afirmar que unos de los fundamentos de la dominación imperialista era de orden tecnológico y que la desigualdad en el acceso a la modernidad científica explicaba el éxito de los países occidentales en detrimento de las otras regiones del mundo. La presencia del pasado no era, por lo tanto, una simple referencia temporal en el marco de una redefinición identitaria. Más bien, ésta rescató acontecimientos lejanos en el tiempo y a menudo dramáticos (la conquista, la colonización, la esclavitud, la explotación de los pueblos autóctonos, las guerras, etcétera) como recuerdos vívidos y presentes en provecho de una política activa. Aquí, esta visión teleológica del pasado se jugaba sobre temporalidades diferenciadas, con el fin de favorecer una reapropiación del pasado suficientemente fuerte que les permitiera a los antiimperialistas tomar conciencia de que vivían "la historia en el presente". Los grandes hechos históricos como la Conquista, por ejemplo, sirvieron para demostrar empíricamente las diferencias de orden militar presentes en el tiempo y a subrayar así, que la lucha antiimperialista era igualmente un combate por un mejor acceso a los recursos de la modernidad científica.

Los textos sobre el período colonial y precolonial insistían en particular en la necesidad de reivindicar las raíces indígenas, ${ }^{35}$ con énfasis en la alegoría del "pueblo" combativo expresada durante la Revolución mexicana y la Reforma Universitaria de Córdoba bajo una forma polimorfa en la que se fundían las clases medias, los estudiantes, los pequeños propietarios y los intelectuales. Dada la importancia de los símbolos dentro de los círculos antiimperialistas, las revistas Repertorio Americano y Amauta hicieron de los pueblos autóctonos la encarnación de las injusticias sociales en el ámbito latinoamericano. Se esforzaron por escapar de las influencias culturales y académicas tradicionales e hicieron de la palabra "Indoamérica" la encarnación lexical de un espacio contestatario propio. El uso de esta denominación, retomada en muchos de los números ${ }^{36}$ buscaba mostrar su profundo apego a la "raza" en la línea de José Vasconcelos, así como jugar sobre su pluralidad de sentidos. Sin ser exhaustivo, el término "indoamérica" debía contener potencialmente una cantidad incalculable de reivindicaciones sufi-

34 Mariátegui, “La evolución de la economía peruana”, Amauta, núm. 2, 1926, pp. 29-30. Romero, "Sobre las huellas de los conquistadores”, Amauta, núm. 23, 1929, pp. 12-15.

35 Orrego, “Americanismo y peruanismo”, Amauta, núm. 9, 1926, p. 5; Mayer de Zulen, “América para la humanidad”, Amauta, núm. 9, 1927, pp. 14-15.

36 Carranza, “El indo-hispanismo”, Amauta, núm. 18, 1929, p. 94. Arciniegas, “Carta a Haya de la Torre”, Repertorio Americano, núm. 1, 1934, pp. 79-80. 
cientemente amplias como para seducir y politizar a diversos actores de los frentes antiimperialistas, así como a otros vanguardistas comprometidos con la voluntad de redibujar los espacios político-culturales en la región.

Esta movilización terminológica se inscribía igualmente en un régimen de historicidad dominante, marcado tanto por la obsesión de una eternidad precolombina jamás alejada de los intereses políticos, como por la búsqueda de una tradición cultural eterna que podíamos encontrar en el arte de esa época. Las utilizaciones indigenistas de los símbolos precolombinos redibujaron así el pasado, ya que se trataba de afirmar que existía una cultura nativa americana eterna y auténtica, por encima de los siglos de colonización europea. Muchos de los grandes historiadores latinoamericanos, como el peruano Jorge Basadre (1903-1980) o el colombiano Germán Arciniegas (1900-1999), guiaron durante su juventud este movimiento de "reinvención de la tradición”, ${ }^{37}$ seleccionando eras históricas y dividiendo luego el pasado en períodos secuenciales. Recordemos como ejemplos los artículos "Sumario de Tawantisuyo", ${ }^{38}$ de Luis Valcárcel o "Los Amautas en la historia peruana” ${ }^{39}$, de Eugenio Garro, que relataron la época del Tahuantinsuyo como una edad de oro, en oposición a la gran catástrofe encarnada por la Conquista. Esos autores utilizaron la metodología histórica con el fin de permanecer en el campo de la especialización académica reivindicada por los editoriales de las revistas. Variaron únicamente los ángulos de observación para poder inscribir mejor sus textos dentro de sus disciplinas, aprovechando al mismo tiempo su colaboración para valorizar otros territorios (Asia en particular). ${ }^{40}$

Este anclaje en el tiempo se planteaba directamente como una inscripción histórica. Desde su primer editorial, el director de Amauta, José Carlos Mariátegui, afirmó abiertamente que los intelectuales debían integrar América Latina dentro de una nueva temporalidad político-cultural. Los números siguientes de la revista se mantuvieron dentro de esta óptica, caso del artículo "La Batalla de nuestra generación”, de Edwin Elmore, quien señalaba la existencia de una generación continental que ya había empezado a cambiar la situación:

La ola de la protesta ha ido creciendo de Sur a Norte. Con Pérez Triana y Sanin Cano en Colombia; con Saenz Peña. Ugarte e Ingenieros en la Argentina. Con menos vigorosos acentos repartidos en todo el Continente, el coro de

37 Hobsbawm, Ranger, The Invention of Tradition.

38 Valcárcel, "Sumario de Tawantisuyo", Amauta, núm. 13, 1928, pp. 29.

39 Garro, “Los Amautas en la historia peruana”, Amauta, núm. 3, 1926, pp. 38-39.

40 Martínez de la Torre, “China contra el imperialismo”, Amauta, núm. 16, 1928, pp. 43-44; Andrade, "El imperialismo y la lucha de los pueblos coloniales”, Amauta, núm. 15, 1928, pp. 32-35. 
alarma ha adquirido en nuestros días el ímpetu marcial de un vigoroso andante. Puede el profeta de Ariel dormir tranquilo. La Ciudad Futura que él soñara vive en la mente de quienes han de ser sus fundadores. Frente a los Babeles de las naciones bélicoindustriales alzarán en América los herederos de los épicos conquistadores la torre ideal de una nueva cultura y una civilización salvadora de lo humano. ${ }^{41}$

La búsqueda de veracidad y la puesta en común de los elementos históricos compartidos a nivel continental fueron los dos principales desafíos memoriales llevados a cabo por las revistas antiimperialistas. Estos objetivos se fundaron sobre un trabajo de sedimentación temporal previa, consistente en la definición de recuerdos compartidos, frente a la heterogeneidad de la cultura latinoamericana. La totalidad de los discursos históricos estuvieron marcados por una concepción del tiempo enraizada en una visión moral de la historia. De esta forma, respondían a una obligación de denuncia pública de los males del pasado, frente a las atrocidades cometidas desde la Conquista, aplicando preceptos políticos del filósofo argentino José Ingenieros (18771925), cuya obra póstuma Fuerzas Morales, jugó un rol decisivo en la estructuración del pensamiento antiimperialista latinoamericano. Las ideas de Ingenieros introdujeron entonces una lectura nacionalista del pasado latinoamericano, basada justamente en la idea de que la comprensión del pasado era indispensable para la reestructuración del modelo nacional en América Latina. Su influencia se hizo sentir en la publicación de numerosos artículos del autor en Amauta, quien reafirmaba permanentemente su voluntad de construir un crisol nacional libre de toda influencia europea. ${ }^{42}$

La transformación de personajes históricos en héroes de su tiempo estuvo marcada por posicionamientos radicales contra el imperialismo norteamericano y sus cómplices autoritarios locales juzgados como enemigos históricos. Para Francisco Javier Fernandois, ex presidente de la Federación de estudiantes de Chile, esta lucha era más que un deber de esclarecimiento de los males del presente heredados del pasado. Era, por encima de todo, una verdadera ética de responsabilidad que la joven generación latinoamericana abierta al mundo debía conducir como un movimiento de liberación, con el objeto de completar definitivamente un ciclo iniciado a principios del siglo XIX:

Para ello, es menester el sacrificio de nuestra generación, con objeto de preparar las condiciones que hagan posible el cumplimiento de la misión que a Latino-América el destino le ha deparado, porque si bien es cierto que Bolívar 


\begin{abstract}
y sus nobles compañeros nos legaron la independencia, no lo es menos que, en el trascurso de cien años su obra ha sido desnaturalizada y casi destruida por completo por los hombres, generalmente mediocres y casi siempre canallas que han gobernado los distintos países en que, para favorecer sus mezquinos intereses personales o de círculo, han dividido sangrientamente a nuestra nación. ${ }^{43}$
\end{abstract}

Este tipo de inmersión temporal en un tiempo remoto tenía una gran afinidad con el tiempo revolucionario, ya que formaba parte de una sensibilidad política y de una cultura ideológica que buscaban recuperar la pureza de lo "americano". El proyecto de ambas revistas estaba, por lo tanto, asociado a un trabajo de retrospección. Ciertos posicionamientos de Amauta, en particular, se reclamaban de una tradición de justicia social e histórica que legitimaba la necesidad de una revolución como un acto de "liberación” de América Latina. Lo que valía a nivel de la transformación histórica valía también a nivel económico puesto que se trataba de tomar antes que nada el control de las fuerzas productivas en manos de la oligarquía y del imperialismo. Las medidas promovidas por personajes como José Carlos Mariátegui buscaban recuperar los derechos "naturales" del pueblo americano como quien recupera los bienes de una región que fue despojada de su propiedad a raíz de las invasiones extranjeras. A diferencia de otros procesos revolucionarios que buscaban crear un "hombre nuevo" (el fascismo, el estalinismo, la Revolución cultural de Mao), el proyecto vanguardista de las revistas culturales antiimperialistas era más bien una regeneración de la "raza” (para hablar como José Vasconcelos) mediante un verdadero cambio hegemónico. Según los autores de estas publicaciones, este proceso implicaría para ello crear una nueva temporalidad que combinaría desde luego lo inmutable de la historia nacional (tiempo precolonial) y la creencia en un porvenir igualitario inspirado en el horizonte antiimperialista.

\title{
CONCLUSIÓN
}

Los discursos de ruptura histórica imponen siempre una lectura ideológica del pasado. Juegan incluso un rol performativo dentro de una óptica de politización permanente del tiempo. Ideologizando símbolos, hechos y personajes históricos, las revistas antiimperialistas del inicio del siglo Xx reflejaban las luchas del presente y una construcción del futuro en la pluma de intelec-

43 Fernandois, "Votos Americanistas de las Juventudes del Perú y Chile”, Amauta, núm. 7, 1927, p. 34. 
tuales que se autodefinían como una “generación histórica”. La memoria reivindicada era entonces, política y expresaba la importancia de la idea de subversión frente al orden establecido.

El pasado colonial fue sujeto de múltiples interpretaciones, algunas de ellas contradictorias, por el hecho de representar tanto un período de dominación como una coyuntura de gran riqueza cultural. Se le interpretó según una matriz ideológica dentro de la cual se reunían, con mayor o menor intensidad, la rememoración activa de una herencia cultural y una tensión política frente al legado colonial. El pasado pre-colombino, por el contrario, gozó de una amplia unanimidad en el seno de los aparatos político-intelectuales, puesto que su condición de "tiempo perdido" permitía darle una connotación dramática a la historia latinoamericana. En las revistas de la emancipación, la evocación del pasado revitalizó los discursos políticos que buscaban la instauración de un nuevo modelo de sociedad no capitalista. Basculando de esta manera dentro de la ideología, la historia no pareció tener entonces otra salida que la emancipación.

\section{BIBLIOGRAFÍA}

Ansell, Christoher, "Symbolic Networks: The Realigment of the French Working Class, 1887-1894”, The American Journal of Sociology, núm. 2, 1997, pp. 359-390. DOI: https://www.doi.org/10.1086/231211.

Bergel, Martín, “América, pero desde abajo. Prácticas y representaciones intelectuales de un ciclo histórico latinoamericanista (1898-1936)”, Cuadernos de Historia, núm. 36, 2012, pp. 7-36. DOI: https://www.doi.org/10.4067/S071912432012000100001.

_ _ "Para una historia de la no-lectura en América Latina. Los usos de los objetos impresos en el proceso de popularización del Partido Aprista Peruano (1931-1945)”, Políticas de la Memoria, núm. 17, 2017, pp. 167-187.

Boissevain, Jeremy, Friends of friends: networks, manipulators and coalitions, Oxford, Blackwell, 1974.

Casaús Arzú, Marta Elena; Pérez Ledesma, Manuel (eds.), Redes intelectuales y formación de las naciones en España y América Latina (1890-1940), México, Ediciones de la Universidad Autónoma de Madrid, 2005.

Chapoutot, Johan, “L’historicité nazie”, Vingtième siècle, núm. 117, 2013, pp. 43-55. https://www.doi.org/10.3917/vin.117.0043.

Conrad, Sebastian, What is Global History ?, Princeton, Princeton University Press, 2016.

Compagnon, Olivier, L'Adieu à l'Europe. L'Amérique Latine et la Grande Guerre (Argentine et Brésil, 1914-1939), Paris, Fayard, 2013. 
De la Fuente, José, "Victor Raúl Haya de la Torre, el APRA y el indoamericanismo”, Cuyo. Anuario de Filosofía Argentina y Americana, núm. 24, 2007, pp. 139164.

Devés Valdés, Eduardo, Hacia la constitución de una comunidad intelectual, Santiago, Universidad de Chile, 2007.

Dumont, Juliette, Diplomatie culturelle et fabrique des identités. Argentine, Brésil, Chili (1919-1946), Rennes, Presses Universitaires de Rennes/IDA, 2009.

Emirbayer, Mustapha, "Manifiesto for a relational sociology", The American Journal of Sociology, núm. 2, 1997, pp. 281-317. DOI: https://www.doi.org/10.1086/231209.

Funes, Patricia, Salvar la nación: intelectuales, cultura y política en los años veinte latinoamericanos, Buenos Aires, Prometeo Libros Editorial, 2006.

Gallichio, Marc, The African American Encounter with Japan and China: Black Internationalism in Asia, 1895-1945, Chapell Hill, University Of North Carolina Press, 2000.

Giddens, Anthony, The consequences of modernity, Stanford, Stanford University Press, 1990.

Goebel, Michael, Interwar Paris and the Seeds of the Third World Nationalism, New York, Cambridge University Press, 2015.

, "Fighting and Working in the Metropole. The Nationalizing Effects of the First War thoughout the French Empire, 1916-1930”, Bley, Helmut Bley; Kremers, Anorthe (eds.), The World During the First War, Essen, Klartext Verlag, 2014, pp. 101-111.

Hartog, François, Régime d'historicité. Présentisme et expérience du temps, Paris, Seuil, 2003.

Hobsbawm, Eric; Ranger, Terence, The Invention of Tradition, Cambridge, Cambridge University Press, 1983.

Hodge Dupré, Eduardo, "La defensa continental de América Latina en el pensamiento de Manuel Ugarte y Víctor R. Haya de la Torre (1900-1945)”, Latinoamérica. Revista de Estudios Latinoamericanos, núm. 52, 2011, pp. 139-164.

Klengel, Suzanne; Ortiz Wallner, Alexandra, "Sur / South Poetics of Thinking Latin America / India, Iberoamericana, Madrid, 2016.

Löwy, Michael, “Temps messianique et historicité révolutionnaire chez Walter Benjamin”, Vingtième siècle, núm. 17, 2013, pp. 106-118. DOI: https://www.doi.org/10.3917/vin.117.0106.

Manela, Erz, The Wilsonian Moment: Self-Determination and the International Origins of Anticolonial Nationalism, New York, Oxford, Oxford University Press, 2009.

Louro, Michele, Comrades against Imperialism: Nehru, India and Interwar Internationalism, Cambridge University Press, Cambridge, 2018. DOI: https://www.doi.org/10.1017/9781108297615. 
Ocampo, Victoria, Tagore en las barrancas de San Isidro, Buenos Aires, Sur, 1961. Pita, Alexandra; Marichal, Carlos, Pensar el antiimperialismo. Ensayos de historia intelectual latinoamericana (1900-1930), México, El Colegio de México, Universidad de Colima, 2012.

Pita, Alexandra (comp.), Redes transnacionales en América Latina durante la entreguerra, Colima, Ciudad de México, Miguel Ángel Porrúa, 2016.

—_, "Fronteras simbólicas y redes intelectuales. Una propuesta”, Historia y Espacio, núm. 49, 2017, pp. 39-63.

Prashad, Vijay, The poorer Nations: a possible history of the Global South, London, Verso, 2012.

Siskind, Mariano, Cosmopolitan Desires: Global Modernity and World Literature in Latin America, Evanston, Northwestern University Press, 2014. DOI: https://www.doi.org/10.2307/j.ctv4cbg63.

Taracena, Arturo, "La Asociación General de Estudiantes Latinoamericanos de París (1925-1933)”, Anuario de Estudios Centroamericanos, núm. 5, 1989, pp. 6180 .

Yankelevich, Pablo, "Las redes de solidaridad latinoamericana: José Ingenieros y Alfredo Palacios frente a la Revolución Mexicana”, Revista Mexicana de Sociología, núm. 4, 1996, pp.127-149.

DOI: https://www.doi.org/10.2307/3541044. 